\title{
OBSERVATIONS OF THE OUASI 2-DAY WAVE FROM THE HIGH RESOLUTION DOPPLER IMAGER ON UARS
}

\author{
D. L. Wu, P. B. Hays, W. R. Skinner, A. R. Marshall, M. D. Burrage, R. S. Lieberman, and D. A. Ortland \\ The University of Michigan \\ Department of Atmospheric, Oceanic and Space Sciences
}

\begin{abstract}
A strong westward traveling oscillation, with a period of 2 days and zonal wave number 3 , is observed in the mesospheric and lower thermospheric winds from the High Resolution Doppler Imager on the Upper Atmosphere Research Satellite. The important events happen in January, July, and September/October, of which the occurrence in January is the strongest with an amplitude over $60 \mathrm{~ms}^{-1}$. Detailed analyses for the periods of January 1992 and January 1993 reveal a cause-and-effect relationship in the wave developing process at $95 \mathrm{~km}$. The global structures of the wave amplitude and phase are also presented.
\end{abstract}

\section{Introduction}

Over the last two decades a number of observations of the quasi-two-day wave (1.8-2.2 days; hereafter the 2-day wave) have been reported from ground-based stations, rockets and satellites. The ground-based observations consist mainly of radar wind measurements over a wide range of latitudes [Müller and Kingsley, 1974; Salby and Roper, 1980; Manson and Meek, 1990; Vincent and Lesicar, 1991; Fritts and Isler, 1992; Tsuda et al., 1988]. The 2-day wave amplitude of the meridional component was found to be quite large $\left(50 \mathrm{~ms}^{-1}\right)$ in the meteor region but intermittent with a lifetime of about 20-30 days. Sometimes, the oscillation could reach even up to the ionosphere [Chen, 1992]. At mid-latitudes a large amplitude was usually observed one month after the summer solstice [Craig et al. 1980; Clark, 1989] while at the tropical and subtropical sites [Harris and Vincent, 1993; Fritts and Isler, 1992] the wave appeared in both solstice periods. In general, the January/February event was stronger than one in July/August. The satellite data of Nimbus 5 [Rodgers and Prata, 1981] and Nimbus 7 [Burks and Leovy, 1986], on the other hand, provided a global and long-term study of the 2day wave and helped confirm its zonal wavenumber 3 character

The origin of such a transient 2-day oscillation remains unclear. However, the eigenperiod studies of the Rossbygravity normal modes [Salby, 1981; Hagan et al., 1993] suggested that the mode $(3,0)$ could be the major carrier of the 2-day wave. The symmetric eigenstructure of the mode, in the presence of a background mean wind and temperature, was slightly distorted in solstice and the amplitude was enhanced remarkably in the summer meteor regions. An alternative mechanism proposed by Plumb [1983] emphasized the role of the fast growing baroclinic instability above the summer stratospheric easterlies. In this theory, the 2-day wave is believed to be a product of the instability. Reviews of the phenomenon have been presented by Miiller and Nelson [1978], Salby [1984] and Vincent [1984].

This paper presents the recent results of the 2-day wave observed by the High Resolution Doppler Imager (HRDI) on board the Upper Atmosphere Research Satellite (UARS). The data consist of the wind measurements in the mesosphere/lower thermosphere (MLT) region from $65 \mathrm{~km}$ to $105 \mathrm{~km}$. An intensive study of the events in January 1992 and

Copyright 1993 by the American Geophysical Union.

Paper number 93GL03008

0094-8534/93/93GL-03008\$03.00
January 1993 are carried out to show the global distribution and temporal variation of the wave amplitude and phase.

\section{Data analysis}

HRDI is a triple etalon Fabry-Perot interferometer that determines winds with an accuracy of $5 \mathrm{~ms}^{-1}$ by resolving the Doppler shift of $\mathrm{O}_{2}$ emission lines (around $7620 \AA$ ) in the MLT region. Details of the instrument and the calibration procedures can be found elsewhere [Hays, et al., 1993; Burrage, et al., 1993]. HRDI has been measuring winds since November 1, 1991 and divides the observing time equally between the stratospheric mode $(10-40 \mathrm{~km})$ and the MLT mode $(50-115 \mathrm{~km})$. Until June 1993 , the regular observing scheme for the MLT region was to scan all altitudes during the daytime between $65 \mathrm{~km}-105 \mathrm{~km}$ with a $2.5 \mathrm{~km}$ increment. Subsequently, the altitude range was extended to $50-115 \mathrm{~km}$ with the same height resolution. In the nighttime, HRDI measurements are limited to one altitude $(-95 \mathrm{~km})$ because the observed nightglow emission is restricted to a narrow layer. In addition to performing the altitude scanning, the gimbaled HRDI telescope is capable of moving in azimuth and allowing views of both sides of the satellite track. The latitudinal coverage is determined by the HRDI viewing direction and the UARS orbit which is circular at an altitude of $585 \mathrm{~km}$ and an inclination of $57^{\circ}$. The orbital precession allows a complete sampling of local times about every 36 days. The HRDI observing plans are made on a daily basis. Except during special campaigns, generally, the MLT region is viewed every other day.

Due to the HRDI's special day-and-night viewing plans, the samples sometimes are not uniformly spaced and can have a large gap. Therefore, a least-square spectral analysis method is employed to resolve the 2-dimensional space-time spectra. The basic idea of the technique is to fit parameters $A$ and $B$ so as to minimize the departure between the desired functions and observations [for an example, Bevington 1969 ], which is given by

$$
\chi^{2}=\sum_{i} \frac{\left(A \cos 2 \pi\left(\sigma t_{i}+s \lambda_{i}\right)+B \sin 2 \pi\left(\sigma t_{i}+s \lambda_{i}\right)-y_{i}\right)^{2}}{\varepsilon_{i}^{2}}
$$

where $y_{i}$ is the measurement, with an error $\varepsilon_{i}$, obtained at universal time $\mathrm{t}_{\mathrm{i}}$ (days) and longitude $\lambda_{\mathrm{i}}$ (normalized to unity). $\sigma$ and $s$ are, respectively, the frequency (days $s^{-1}$ ) and the zonal wavenumber of the oscillation. Fitting is performed at every latitude circle and the parameters $A$ and $B$ yield the amplitude $\sqrt{\mathrm{A}^{2}+\mathrm{B}^{2}}$ and the phase $\tan ^{-1}(\mathrm{~B} / \mathrm{A})$ for that latitude. Spectral scans have been carried out for HRDI data by tuning $\sigma$ and $s$ to search significant wave components. The pair, $(\sigma, s)=(0.5,3)$, has a large amplitude response in January and is used to stand for the 2-day wave throughout this paper. Because the 2-day wave is such a transient phenomenon, a running 5-day interval is used in the spectral analysis. However, this short time interval yields a coarse spectral resolution, which means that the 52 hrs 2 -day wave can still contribute $80 \%$ of its amplitude to the exact 2-day wave. 
At a given latitude circle, daily observations can be taken at very different longitudes and universal times but they usually are limited in local time. The HRDI sampling schemes may be divided roughly into three cases in terms of the sampling frequency in local time each day. (I) Two local times separated approximately by $12 \mathrm{hrs}$ are sampled each day, corresponding to the HRDI day-and-night sampling in the equatorial region at $95 \mathrm{~km}$. (II) Only one local time is sampled each day, corresponding to the period when only continuous daytime or nighttime data are available. (III) One local time is sampled every other day, which represents the situation of the regular HRDI MLT viewing. The aliasing problems associated with each case are different and complicated. For a simple and uniform sampling case the aliasing behavior can be well explained by the so-called asynoptic sampling theory [Salby, 1982]. But for irregular sampling, simulations are generally required to resolve the distribution and strength of aliases. Because the satellite sampling is always accompanied by the aliasing problem, a spectral peak can be interpreted as a wave component only when all of its aliases are assumed not to be a realistic atmospheric wave and may be ignored [Lait and Stanford, 1988]. However, this assumption sometimes does not hold for every alias. In order to identify possibly destructive aliases, spectral scans are made for each of the three cases with artificial data. As a result, all the 2-day wave aliases are ignorable under case I and II. In case III, however, the 2-day wave can be partially affected by non-migrating tides and other slowly moving planetary waves therefore any spectral significance out of this sampling must be treated with caution.

\section{Results}

The 2-day wave amplitudes are shown in Figure 1 and they are derived from the spectral analysis with sliding 5-day intervals. The equatorial $\left(10^{\circ} \mathrm{S}-10^{\circ} \mathrm{N}\right)$ amplitudes of the meridional wind are presented because they have a larger wave response [Harris and Vincent, 1993] and serve as a good indicator of the wave event in the meteor region. At $95 \mathrm{~km}$ the 2-day wave is better sampled with both daytime and nighttime data. During January 1992 and January 1993, strong 2-day oscillations (over $60 \mathrm{~ms}^{-1}$ ) occur in the MLT region and last about 30 days. A weaker peak $\left(-30 \mathrm{~ms}^{-1}\right)$ is observed in July 1993, which is consistent with radar observations [Harris and Vincent, 1993; Fritts and Isler, 1992]. Another event, with an amplitude of $40 \mathrm{~ms}^{-1}$ and a

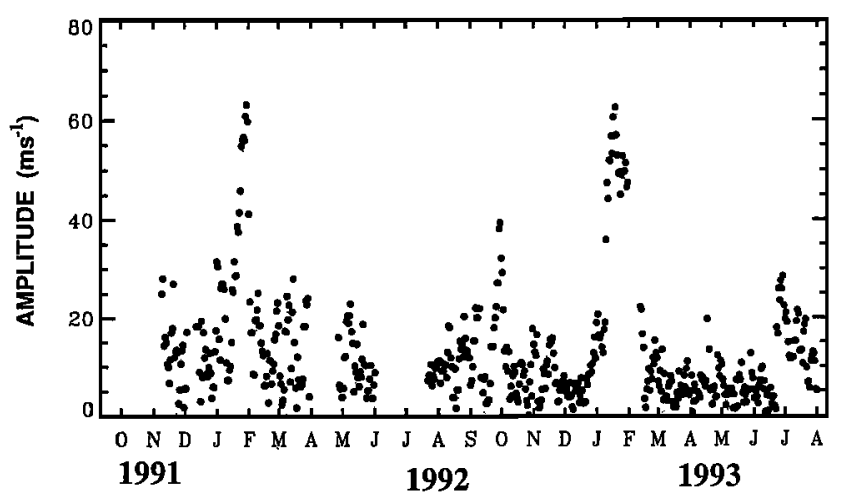

Fig.1. The 2-day wave amplitudes of the meridional component at an altitude of $95 \mathrm{~km}$ in the equatorial region $\left(10^{\circ} \mathrm{S}-10^{\circ} \mathrm{N}\right)$. The fitting is carried out with sliding 5-day intervals including both daytime and nighttime measurements. The confidence level varies from $10 \mathrm{~ms}^{-1}$ to $20 \mathrm{~ms}^{-1}$ depending on the sampling cases. Major events occur in January, July and September/October.
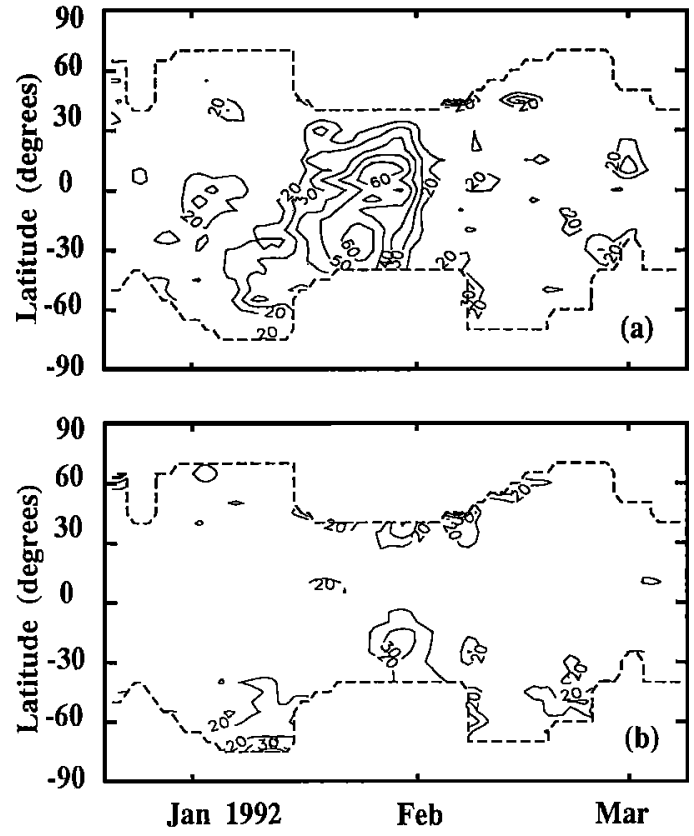

Fig.2. Amplitudes of meridional (a) and zonal (b) components at $95 \mathrm{~km}$ in the beginning of the year of 1992 . Both daytime and nighttime data are used in analysis. Dash lines mark the limiting latitudes of the HRDI's sampling. Contours start from $20 \mathrm{~ms}^{-1}$ at $10 \mathrm{~ms}^{-1}$ intervals.

duration of 15-20 days, happens around September/October 1992 , but it has received little attention previously. This event is interesting because of its time of appearance during which the forcing mechanism could be quite different from that in solstice. Moreover, the October 2-day wave is not only evident in the HRDI winds but also in the radar data [Salby and Roper, 1980; Harris and Vincent, 1993].

The large data breaks in Figure 1 (Mar.31-Apr.24, 1992; Jun.3-Jul.21，1992; Feb.1-Feb.11，1993) are due to malfunctions in either the instrument or the satellite. At 95km, most sampling situations throughout Nov'91-Jul'93 correspond to either case I or II. During the January 1992 and January 1993, HRDI was conducting the mesospheric campaigns, allowing the 2-day wave to be resolved with greater confidence. In some periods, such as Nov.20-28 1991, May, late July, August, and September 1992, the samplings correspond mainly to case III but the amplitudes turn out to be insignificant anyhow. Simulations have been made to retrieve the 2-day wave amplitude from the same sampling conditions but with artificial data, in which the diurnal and semidiurnal tides, 5-, 10-, and 16-day waves are incorporated. The results show that the confidence level varies from $10 \mathrm{~ms}^{-1}$ in sampling case I to $20 \mathrm{~ms}^{-1}$ in case III.

The detailed changes in the wave amplitudes at $95 \mathrm{~km}$ are presented in Figure 2 and Figure 3 for the beginning of 1992 and 1993, respectively. In spite of a 10-day gap in 1993 data, the onset of the 2-day motion is very repeatable in the two periods. The oscillation is induced earlier at higher summer latitudes before it develops into the middle and lower latitudes. The meridional amplitudes in late January are slightly asymmetric about the equator and biased towards the summer hemisphere, which agrees in general with the theoretical expectation of the distorted $(3,0)$ eigenstructure [Salby, 1981; Hagan, et al, 1993]. In early January the wave activities basically reside at higher summer latitudes, which may be related to the baroclinical instability suggested by Pfister [1985]. The zonal component shows smaller amplitudes with two peaks at latitudes of $30^{\circ} \mathrm{S}$ and $30^{\circ} \mathrm{N}$. The 

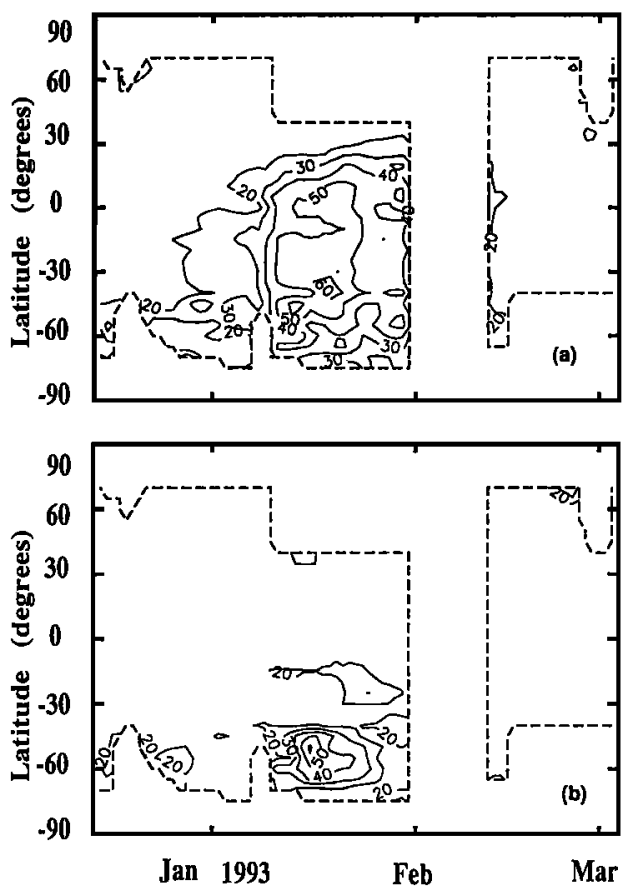

Fig.3. As in Figure 2, but for 1993.

large zonal amplitudes at high latitudes in Figure 3 imply that the 2-day oscillation tend to be more zonal there. This phenomenon is clearer in a vector plot such as Figure 4.

In Figure 4 the 2-day wave in January 1993 is reconstructed for several short periods in the absence of a
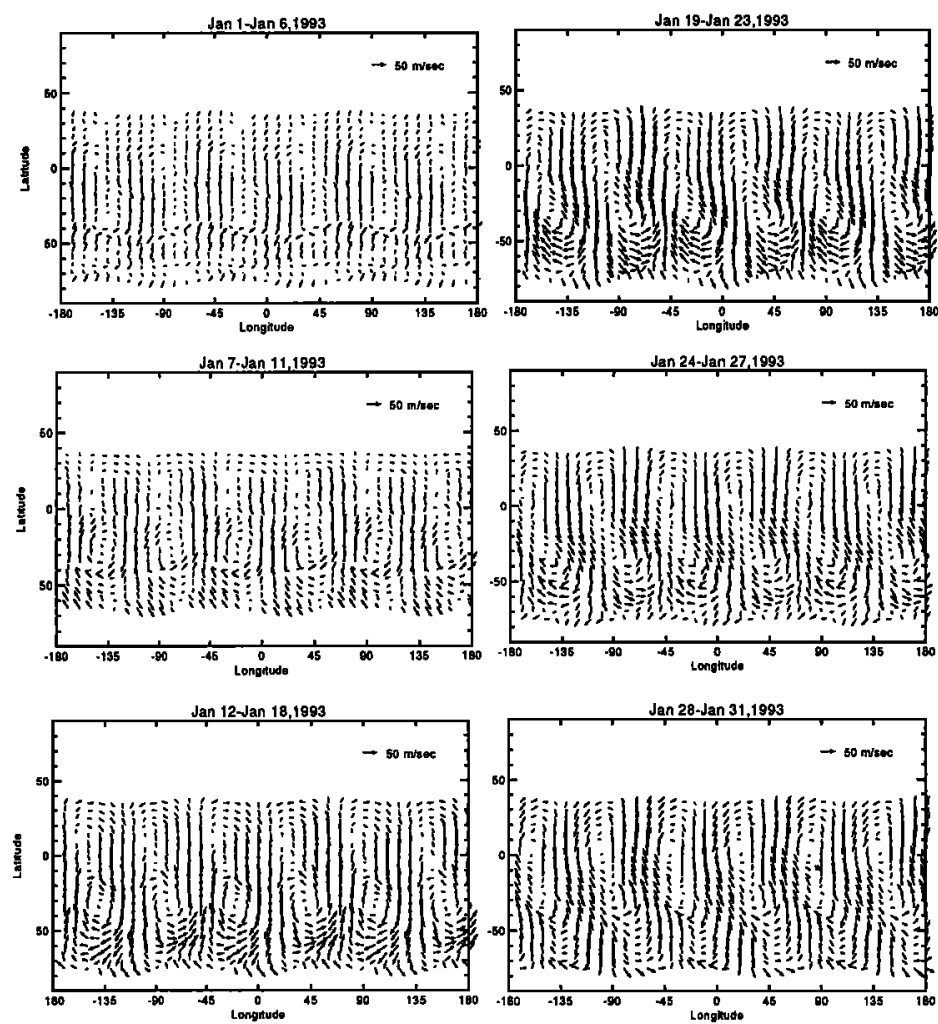

Fig.4. Vector plots of the reconstructed 2-day wave without background winds during January 1993 . The 2-day wave first starts at higher summer latitudes and disperses rapidly into middle and lower latitudes to form a global motion. The motions are presented at universal time 0:00.
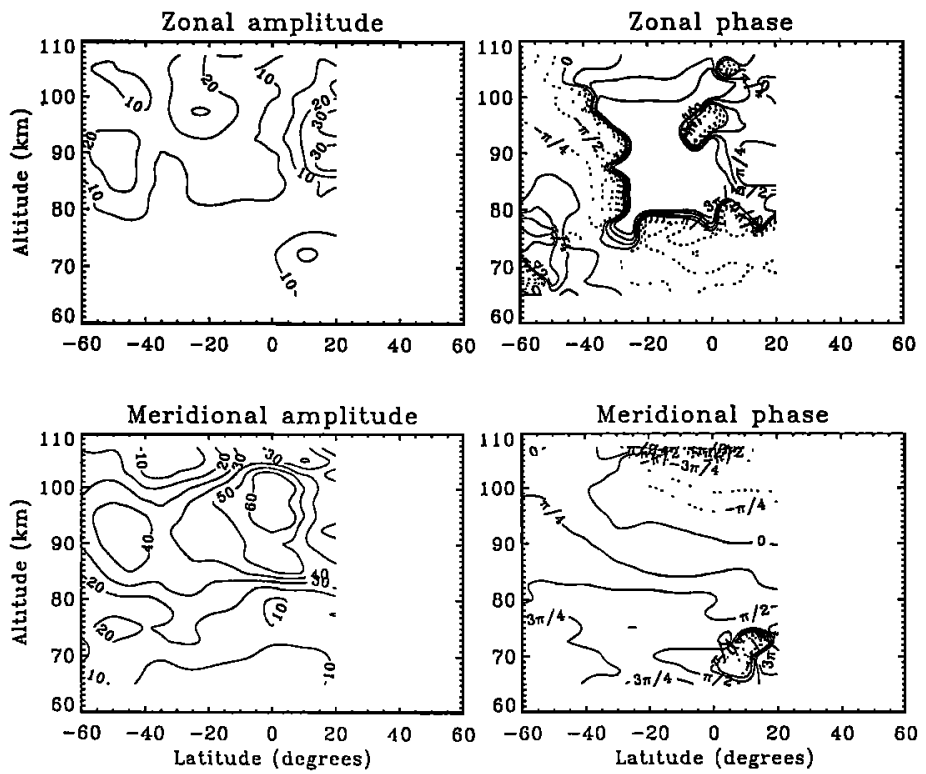

Fig.5. Global distribution of zonal (upper panel) and meridional (lower panel) components during January 24-31, 1993. The mesosphere was viewed continuously during this period but only daytime data are used here. Contours are at $10 \mathrm{~ms}^{-1}$ intervals for amplitudes and $\pi / 4$ intervals for phases.

background mean wind. The wave amplitudes and phases are obtained from the spectral analysis of both daytime and nighttime data. As shown in time sequence, the event is not quite noticeable until Jan.7-11 when cellular structures are first formed and centered at $\sim 30^{\circ} \mathrm{S}$. Shortly after the first appearance in the southern atmosphere, the 2-day wave motion advances northward and crosses the equator. A slight phase shift at $15^{\circ} \mathrm{S}$ divides the motion into two parts: one is centered at the equator while another is at $\sim 30^{\circ} \mathrm{S}$. By the end of January, the structure at higher latitudes gradually reduces its strength and joins together with the equatorial motion to form a larger cell.

The global structures of the amplitude and phase for the period of January 24-31 1993 are presented in Figure 5. Both zonal and meridional amplitude distributions are in general accord with the distorted eigenstructure of the normal mode $(3,0)$ [Salby, 1981; Hagan, et al, 1993]. As expected by theory, around the equator the zonal wind component displays a node whereas the meridional wind exhibits a maximum. The peak value of the meridional amplitude is about $65 \mathrm{~ms}^{-1}$ at $98 \mathrm{~km}$. The meridional phases are tilted with respect to height and manifest a downward progression characteristic. The vertical wavelength tends to be shorter at lower latitudes than at higher latitudes.

\section{Discussion}

Based on the first 21 months of HRDI wind observations, we have shown that the 2-day oscillation sometimes plays a dominating role in the middle and upper atmospheric dynamics. The strongest event occurred in January with an amplitude exceeding $60 \mathrm{~ms}^{-1}$. The evolution at $95 \mathrm{~km}$ revealed a cause-and-effect relationship in the process of the wave development, which may help link the different views on the wave formation. Studies of a resonant eigenstructure of the Rossby-gravity normal mode $(3,0)$ [Salby, 1981; Hagan et al., 1993] concluded that the enhanced wind amplitudes in the meteor region are sensitive to the background mean wind and temperature structure. Hence, the evolution of the background conditions could give rise to a considerable 
change in the dynamic structure of the 2-day wave. However, these normal mode studies did not provide much information on the wave origin because the normal mode can be excited by various forcings. On the other hand, the stability analyses [Plumb, 1983; Pfister 1985] demonstrated a possible triggering mechanism in which the baroclinically unstable waves, trapped in the mid- and high-latitudes, could excite rapidly growing modes with a zonal wavenumber 3 and a period close to 2 days. Nevertheless, these analyses were made in one hemisphere and do not apply to the equatorial region. In spite of the theoretical shortages, the HRDI observations tend to support such a scenario: the January 2day wave is possibly first induced by the baroclinic instability or some local forcings at higher summer latitudes and disperses into a global response with a structure like the distorted $(3,0)$ mode. However, this study is limited to the data set of the HRDI MLT wind measurements only. More information is expected from the temperatures measured by HRDI and other UARS instruments which will provide a complete picture of the 2-day wave between $20 \mathrm{~km}$ and $115 \mathrm{~km}$. The measured background winds and temperatures will be very useful for better understanding these 2-day wave events and their origin in the future investigations.

Acknowledgments. This work is sponsored by NASA under Contract No. NAS 5-27751. The authors also wish to thank Bob Vincent, Anne Smith, Maura Hagan and Susan Avery for their valuable comments and helpful discussions.

\section{References}

Bevington, P. R., Data Reduction and Error Analysis for the Physical Sciences. McGraw-Hill, 1969

Burrage, M. D., W. R. Skinner, A. R. Marshall, P. B. Hays, R. S. Lieberman, S.J. Franke, D. A. Gell, D. A. Ortland, Y. T. Morton, F.J. Schmidlin, R.A. Vincent, and D. L. Wu, Comparison of HRDI measurements with radar and rocket observations, Geophys. Res. Lett. Vol.20, 1259-1262, 1993

Burks, D and C. Leovy, Planetary Waves Near the Mesospheric Easterly Jet, Geophys. Res. Lett. Vol.13, 193196, 1986

Chen, P.-R., Two-day oscillation of the equatorial ionization anomaly, L. Geophys. Res. 27, 6343-6357, 1992

Clark, R. R., The quasi 2-day wave at Durham $\left(43^{\circ} \mathrm{N}\right)$ : solar an magnetic effects, J. Atmos. Terr. Phys, 51, 617-622, 1989.

Craig, R. L., R. A. Vincent, G. J. Fraser, and M. J. Smith, The quasi 2-day wave in the Southern Hemisphere mesosphere, Nature. 287, 319-320, 1980.

Fritts, D. C. and Isler, J. R., First observations of mesospheric dynamics with a partial reflection radar in Hawaii $\left(22^{\circ} \mathrm{N}\right.$, $160^{\circ}$ W), Geophys. Res. Lett. 19, 409-412, 1992.

Hagan, M. E., J. M. Forbes, and F. Vial, A numerical investigation of the propagation of the quasi-2-day wave into the lower thermosphere, J. Geophys. Res. in press, 1993.
Harris, T. J., and R. A. Vincent, The Quasi-two-day wave observed in the equatorial middle atmosphere. J. Geophys. Res. 98, 10,481-10,490, 1993.

Hays, P. B., Abreu, V. J., Dobbs, M. E., Gell, D. A., Grassl, H. J. and Skinner, W. R., The High Resolution Doppler Imager on the Upper Atmosphere Research Satellite, J. Geophys. Res. in press, 1993

Lait, L. R. and J. L. Stanford, Applications of asynoptic space-time Fourier transform methods to scanning satellite measurements. J. Atmos. Sci. 45, 3784-3799, 1988.

Manson, A. H., and C. E. Meek, Long period (-8-20h) wind oscillations in the upper middle atmosphere at Saskatoon $\left(52^{\circ} \mathrm{N}\right)$ : evidence for non-linear tidal effects, Planet. Space Sci. 38, 1431-1441, 1990.

Müller, H. G. and S. P. Kingsley, On the scale sizes of wind systems in the meteor zone, J.Atmo. Terr. Phys. 36, 18511861,1974

Müller, H. G. and L. Nelson, A traveling quasi 2-day wave in the meteor region, I. Atmos. Terr. Phys. 40, 761-766, 1978.

Pfister, L., Baroclinic instability of easterly jets with applications to the summer mesosphere, J. Atmos. Sci., 42. 313-330, 1985.

Plumb, R. A., Baroclinic instability of the mesosphere: A mechanism for the 2-day wave?, J.Atmos. Sci. 40. 262$270,1983$.

Rodgers, C. D. and A. Prata, Evidence for a traveling 2-day wave in the middle atmosphere, J. Geophys. Res. 86, 9661$9664,1981$.

Salby, M. L., The 2-day wave in the middle atmosphere: observations and theory, L. Geophys. Res. 86, 1981.

Salby, M. L., Sampling theory for asynoptic satellite observations. Part I: space-time spectra, resolution, and aliasing, J_Atmos. Sci. 39, 2577-2600, 1982.

Salby, M. L., Survey of planetary-scale traveling waves: the state of theory and observations, Review Geophys. Space Phys. 22, 209-236, 1984.

Salby, M. L. and R. G. Roper, Long-period oscillations in the meteor region, J. Atmos. Sci. 37, 237-244, 1980.

Tsuda, T., S. Kato, and R. A. Vincent, Long period wind oscillations observed by the Kyoto meteor radar and comparisons of the quasi-2-day wave with Adelaide HF radar, I. Atmos. Terr. Phys. 50, 225-230, 1988.

Vincent, R. A., MF/HF radar measurements of the dynamics of the mesopause region-A review, I.Atmos. Terr. Phys. 46, 961-974, 1984.

Vincent, R. A. and D. Lesicar, Dynamics of the equatorial mesosphere: first results with a new generation partial reflection radar, Geophys. Res. Let. 18, 825-828, 1991.

D. L. Wu, P. B. Hays, W. R. Skinner, A. R. Marshall, M. D. Burrage, R. S. Lieberman, and D. A. Ortland, The University of Michigan, Department of Atmospheric, Oceanic and Space Sciences, Ann Arbor, MI 48109, U.S.A.

(Received: September 21, 1993; accepted: October 18, 1993) 